\title{
Adult Brain Glioblastoma
}

National Cancer Institute

\section{Source}

National Cancer Institute. Adult Brain Glioblastoma. NCI Thesaurus. Code C9375.

A brain glioblastoma that occurs during adulthood. 